\title{
Correlation of Glycated Haemoglobin with Netrin-1 and High Sensitive C-Reactive Proteinin Type 2 Diabetes Melitus Patients
}

\author{
Erika Rosaria $^{1}$, Nurahmi ${ }^{2,3}$, Liong Boy Kurniawan ${ }^{2,4}$ \\ ${ }^{1}$ Program Pendidikan Dokter Spesialis Patologi Klinik Fakultas Kedokteran Universitas Hasanuddin, \\ ${ }^{2}$ Departemen Ilmu Patologi Klinik Fakultas Kedokteran Universitas Hasanuddin, ${ }^{3}$ RSUD Kota Makassar, ${ }^{4}$ RSPTN \\ Universitas Hasanuddin, Makassar
}

\begin{abstract}
Diabetes mellitus is a group of metabolic disease with the characteristic of hyperglycemia that occurs due to abnormal insulin secretion, insulin action or both. Low level inflammation plays a role in the mechanism of type 2 DM. Netrin-1 is a laminin protein group that has anti inflammatory properties. Netrin-1 is a new potential biomarker for diagnosing type $2 \mathrm{DM}$ and its complications. High sensitive C-reactive protein is an acute phase protein produced by the liver in response to proinflammatory cytokines. Glycatedhaemoglobin test is a test recommended by the American Diabetes Association as a marker for diagnosis and predictor of the development of DM complications. The purpose of this study was to determine the correlation between glycatedhaemoglobin with netrin-1 and high sensitive C-reactive proteinin patients with type $2 \mathrm{DM}$.

This cross sectional studyused type 2 DM patients as a sample. Fifty two type 2 DM patients participated in this study. The sample consisted of 21 samples of controlled type 2 DM and 31 samples of uncontrolled type 2 DM. The glycatedhaemoglobin was measured using immunoturbidimetry method, netrin-1 was measured using the ELISA method and hsCRP by immunoturbidimetry method . Data were analyzed statistically with the Mann Whitney and Spearman test.

The results showed that netrin-1 in the uncontrolled type 2 DM group was higher than netrin-1 in the controlled type $2 \mathrm{DM}$ group but there was not statistically significant ( $>0.05)$. High sensitive C-reactive protein in the uncontrolled type 2 DM group was higher than in the controlled type 2 DM group $(p<0.05)$. Glycatedhaemoglobin does not correlate with netrin-1 ( $>0.05)$. Glycatedhaemoglobin was positively correlated with hsCRP with moderate correlation strength $(\mathrm{p}<0.01, \mathrm{r}=0.418)$. Netrin-1 did not correlate with hsCRP $(\mathrm{p}>0.05)$. It was concluded that netrin-1 and hsCRP were higher in uncontrolled DM. The higher glycatedhaemoglobin, the higher hsCRP too.
\end{abstract}

Keywords: DM type 2, glycatedhaemoglobin, netrin-1, hsCRP.

\section{Introduction}

Diabetes mellitus (DM) is a heterogeneous metabolic disorder characterized by the presence of hyperglycemia that occurs due to impairment of insulin secretion, insulin action or both. ${ }^{1,2}$ Chronic hyperglycemia can cause damage to many of the body's organs, leading to disabling and life threatening health complications such as cardiovascular diseases, neuropathy, nefphropathy and retinopathy. ${ }^{3}$
It was estimated that in 2019 there were 463 milion people have diabetes and this number is projected to reach 578 million by 2030 and 700 million by 2045 . Diabetes also estimated to be associated with $11.3 \%$ of global deaths from all causes among adult people. ${ }^{3}$

Glycatedhaemoglobin or HbAlc defined
as haemoglobin which is irreversibly glycated
at one or both N-terminal valines of the beta
chains. ${ }^{4}$ Glycatedhaemoglobin formed in a non


enzymaticglycation pathway by hemoglobin exposure to plasma glucose. ${ }^{4}$ Once a haemoglobin molecule is glycated, it continues to remain in the red blood cell for the rest of its life span. ${ }^{4}$ Glycatedhaemoglobin has been the mostly used and accepted test for monitoring the glycaemic control in individuals with diabetes. ${ }^{4}$ Glycatedhaemoglobin test is recommended by the American Diabetes Association as a marker for diagnosis and predictor of the development of DM complications. ${ }^{5}$ Several studies have shown correlation of $\mathrm{HbAlc}$ with microvascular and macrovascular complications. ${ }^{5}$

Low grade inflammation might play a role in the development and complications of type 2 DM. ${ }^{6}$ Chronic hyperglycaemia induces oxidative stress and chronic inflammatory state. ${ }^{7}$ Chronic hyperglycaemia stimulates the release of various inflammatory cytokines such as IL- 6 and TNF $\alpha$ and induces the secretion of acute phase reactants by the liver. ${ }^{7}$ C-reactive protein is an acute-phase protein, act as an inflammatory marker produced and released by the liver under the stimulation of cytokines. ${ }^{6}$ C-Reactive Protein measured by highly sensitive assays (hsCRP) is a very sensitive marker of inflammatory activity. ${ }^{7}$

Netrin-1 is a laminin group protein encoded by the NTN1 gene which located on 17p13.1 chromosome. Netrin-1 is expressed by the central nervous system, endothelial cells of blood vessels, pancreas, liver, lymph, lungs, intestines and kidneys, which can act as an anti-inflammatory. Netrin-1 can be measured using plasma samples, serum or urine by using enzyme-linked immunosorbent assay (ELISA). ${ }^{8,9,10}$

Chronic inflammation plays role in the pathogenesis of type 2 DM. Glycatedhaemoglobin test is recommended by the American Diabetes Association as a marker for diagnosis and predictor of the development of DM complications. ${ }^{5}$ C-Reactive Protein is an inflammatory protein produced by the liver and have correlation with $\mathrm{HbA1c}$ in many research. Netrin-1 is a protein that has an anti-inflammatory actions. Different animal model and human subjects that were induced/have diabetes alone or along with various microvascular or macrovascular complications showed that the level of netrin is altered in various diseses conditions. ${ }^{10}$ The level of netrin in a diabetes model displayed an inconsistent expression in different clinical studies so we make a study to determine the correlation of glycatedhaemoglobin with netrin-1 and hsCRP in type $2 \mathrm{DM}$ patients.

\section{Materials and Method}

This cross-sectional study was performed to analyze the correlation between glycatedhaemoglobin with netrin-1 and hsCRP in type 2 DM patients at Dr. Wahidin Sudirohusodo General Hospital and Rumah Sakit Unhas in Makassar. This research was conducted during June 2020. The samples of this study were all adult type $2 \mathrm{DM}$ patients diagnosed by Internists based on American Diabetes Association or Perkumpulan Endokrinologi Indonesia, having data for fasting blood glucose, HbAlc, total cholesterol, HDL, LDL, triglycerides and creatinine. Patients with infection, anemia, polycythemia, thalassemia, received a whole bood transfusion or packed red cell within the last 3 months and have a history of heart disease and liver disorder were excluded. Informed consent were obtained from all participants.

All samples were examined for hsCRP levelusing Roche Cobas e 411 automatic chemical analysis at Parahita Laboratory and netrin-1 level by the Enzyme Linked Immunosorbant Assay (ELISA) method in the Laboratory Research Unit of Rumah Sakit Unhas, Makassar.

Data were statistically analyzed using KolmogorovSmirnov normalization test. Mann Whitney test was performed to compare netrin-1 and hsCRP level in controlled and uncontrolled type 2 DM patients. Spearman correlation test was performed to assess the correlation between $\mathrm{HbAlc}$ and netrin-1, HbAlc and hsCRP and between netrin-1 and hsCRP. The results were significant with a $p$ value at $<0.05$. 


\section{Results}

Table 1. Sample characteristics

\begin{tabular}{|l|c|c|c|c|}
\hline Variables & n (\%) & Minimum & Maximum & Mean \pm SD \\
\hline $\begin{array}{l}\text { Gender } \\
\text { Male } \\
\text { Female }\end{array}$ & $\begin{array}{l}36(69.20) \\
16(30.80)\end{array}$ & & & \\
\hline Age (Year) & & 35 & 84 & $59.23 \pm 9.44$ \\
\hline $\begin{array}{l}\text { HbA1c (\%) } \\
\leq 7 \\
>7\end{array}$ & $21(40.38)$ & 5.1 & 12.2 & $7.87 \pm 1.81$ \\
\hline Netrin-1 (pg/dL) & $31(59.62)$ & 183.6 & 2241.4 & $787.30 \pm 405.34$ \\
\hline hsCRP (mg/dL) & & 0.03 & 2.64 & $0.38 \pm 0.46$ \\
\hline
\end{tabular}

The characteristics of this study samples can be seen in table 1. Total of 52 patients participated in this study. The patients age were between 35-84 years with an average of $59.2 \pm 9.4$ years. The HbA1c levels were between $5.1-12.2 \%$ with an average of $7.87 \%$. The sample consisted of $21(40.38 \%)$ type 2 DM controlled group and 31 (59.6\%) uncontrolled type $2 \mathrm{DM}$ group. The lowest and highest netrin-1 level were $183.6 \mathrm{pg} / \mathrm{dL}$ and $2241.4 \mathrm{pg} / \mathrm{dL}$, respectively. The hsCRP level was between $0.03-2.64 \mathrm{mg} / \mathrm{dL}$ with average of $0.38 \mathrm{mg} / \mathrm{dL}$.

Table 2. Netrinand hsCRP Level Based on Group

\begin{tabular}{|l|c|c|c|}
\hline Variabel & Controlled Type 2 DM $(\mathbf{n}=\mathbf{2 1})$ Mean \pm SD & Uncontrolled Type 2 DM $(\mathbf{n}=\mathbf{3 1})$ Mean \pm SD & p \\
\hline Netrin-1 $(\mathrm{pg} / \mathrm{mL})$ & $759,22 \pm 387,20$ & $806,32 \pm 422,42$ & 0,695 \\
\hline hSCRP $(\mathrm{mg} / \mathrm{dL})$ & $0,22 \pm 0,28$ & $0,48 \pm 0,53$ & $0,010^{*}$ \\
\hline
\end{tabular}

*Mann Whitney

Table 2 showed netrin- 1 and hsCRP level based on controlled and uncontrolled DM groups. Netrin-1 was higher in patients with uncontrolled DM $(806.32 \pm 422.42)$ than patients in controlled DM $(759.22 \pm 387.20)$ but not statistically significant ( $p>0.05)$. hsCRP level was found significantly higher in uncontrolled DM group than in controlled DM group, which was 0.48 compared to 0.22 $(\mathrm{p}<0.05)$.

Table 3. Correlation HbA1c with Netrin-1

\begin{tabular}{|c|c|c|c|}
\hline \multirow{2}{*}{} & \multicolumn{3}{|c|}{ Netrin-1 (pg/mL) } \\
\cline { 2 - 4 } & $\mathbf{n}$ & $\mathbf{r}$ & $\mathbf{p}^{*}$ \\
\hline HbA1C $(\%)$ & 52 & 0,136 & $>0,05$ \\
\hline
\end{tabular}

Source: Primary data

* Spearman Test

Table 3 shows that $\mathrm{HbA} 1 \mathrm{c}$ does not have a significant statistically correlation with netrin-1.
Table 4. Correlation HbA1c With hsCRP

\begin{tabular}{|c|c|c|c|}
\hline \multirow{2}{*}{} & \multicolumn{3}{|c|}{ hsCRP $(\mathrm{mg} / \mathrm{dL})$} \\
\cline { 2 - 4 } & $\mathrm{n}$ & $\mathrm{r}$ & $\mathrm{p}^{*}$ \\
\hline $\mathrm{HbA1C}(\%)$ & 52 & 0,418 & $<0,05$ \\
\hline
\end{tabular}

Source: Primary data, *Spearman Test

Table 4 showed a significant correlation between $\mathrm{HbA} 1 \mathrm{c}$ and hsCRP with moderate correlation strengths. This shows that the higher the HbAlc, the higher the hsCRP.

Table 5. Corellation Netrin-1 with hsCRP

\begin{tabular}{|l|c|c|c|}
\hline \multirow{2}{*}{} & \multicolumn{3}{|c|}{ hsCRP (mg/dL) } \\
\cline { 2 - 4 } & $\mathbf{n}$ & $\mathbf{r}$ & $\mathbf{p}^{*}$ \\
\hline Netrin-1 $(\mathrm{pg} / \mathrm{mL})$ & 52 & 0,083 & $>0,05$ \\
\hline
\end{tabular}

Source: Primary data, *Spearman Test 
Table 5 showed correlation between netrin-1 levels and hsCRP in type 2 DM patients. Spearman test showed there were no significant correlation between netrin-1 and $\mathrm{HbAlc}$.

\section{Discussion}

This study was conducted on 52 type 2 DM patients aged between 38-84 years old with mean of 59.2 \pm 9.4 years. This result is in line with Indonesia Riskesdas 2018, which gets the proportion of DM increases with age and the highest is found in the 55-64 years age group. ${ }^{11}$ The sample consist of 35 male patients $(66.7 \%)$ and 17 female patients (33.7\%). International Diabetes Federation report that estimated prevalence of diabetes in women is slightly lower than in men. ${ }^{3}$

Netrin-1 level in uncontrolled type 2 DM group was higher than in controlled type 2 DM group although this results were not statistically significant. This research is in line with research conducted by Yim who found that netrin-1 in DM group was higher than IFG group and healthy group. ${ }^{12}$ Netrin has anti inflammatory action. ${ }^{12}$ Elevated serum netrin-1 is probably attributable to a compensatory response of uncontrolled DM. ${ }^{12}$

There was no significant correlation found between HbAlc and netrin-1 in this study. This result in line with research conducted by Liu in 2018 but contrass to research conducted by Ay, 2016 and Liu, 2016. ${ }^{9,13,14}$ Ay get a positive correlation between netrin-1 and HbA1c while Liu get a negative correlation. ${ }^{9,13,14}$ A reason that distinguish various results of these study might be the differences of patient characteristics. Yim and Liu recruited newly diagnosed type 2 DM patients who had never received anti-diabetic drug therapy. ${ }^{9,12}$ The sample of this research were newly diagnosed type 2 DM patients and those who are already taking anti diabetic drugs.

Moderate positive correlation strength was observed between $\mathrm{HbA} 1 \mathrm{c}$ and hsCRP levels in this study. This result in line with the previous study before. In hyperglycemia state, concentration of advanced glycation end products is elevated and has been shown to activate macrophages, increased oxidative stress and upregulated synthesis of interleukin-1 (IL-1), IL-6 and tumour necrosis factor (TNF- $\alpha$ ) resulting in production of CRP. ${ }^{15}$ These proinflammatory cytokines are engaged with different metabolic pathways applicable to insulin resistance, including insulin direction, receptive oxygen species, lipoprotein lipase activity and adipocyte function. ${ }^{16}$
Netrin-1 did not correlate with hsCRP in this study. The results of this study are in line with research conducted by Yim et al. Yim stated that netrin-1 and CRP were higher in type $2 \mathrm{DM}$ group and IFG group compared to normal group but netrin-1 did not correlate with CRP. ${ }^{12}$ Netrin is a protein secreted by the endothelium which has anti-inflammatory effects while hsCRP is a protein produced by the liver in response to pro-inflammatory cytokine. Netrin will increase or decrease to suppress inflammation. Liu et al reported that higher levels of albumin trigger production of netrin-1 from proximal tubular epithelial cells via extracellular signal regulated kinase (ERK) and Akt kinase patways. ${ }^{13}$ Patientsnephropathy diabetic with increasing albuminuria had higher systolic blood pressure, duration of diabetes, blood urea nitrogen and serum creatinin. ${ }^{13} \mathrm{We}$ suggested that despite of proinflammatory cytokines, there were many factors could affect correlation between hsCRP and netrin-1 suchas albumin, duration of DM and it's therapy.

This study has several limitations. We used heterogeneous samples, did not take healthy controls and did not analyzeIL-1, IL-6 and TNF- $\alpha$ as proinflammatory cytokines.

\section{Conclusion and Suggestion}

There were no statistically significant correlation found between glycatedhaemoglobin and netrin-1 and between netrin- 1 and hsCRP in type 2 DM patients. Glycatedhaemoglobin was positively correlated with hsCRPwith moderate correlation strength. Further randomized prospective studies with homogeneous larger samplesand classify samples into control group (healthy people), controlled and uncontrolled diabetic patients are required to support our findings.

Ethical Clearance: Obtained from Medical faculty ethical committee

\section{Source of Funding: Self}

\section{Conflict of Interest: None}

\section{References}

1. Punthakee Z, Goldenberg R, Katz P. Definition, Classification and Diagnosis of Diabetes, Prediabetes and Metabolic Syndrome. Can J Diabetes 42 (2018) S10-S15

2. PERKENI. Konsensus Pengendalian dan Pencegahan Diabetes Mellitus tipe 2 di Indonesia. 
Jakarta. 2019; 1-72

3. International Diabetes Federation. Diabetes and Cardiovascular Disease. Brussels: International Diabetes Federation; 2019; .p.1-176

4. Gupta A, Kumar D, Rajvanshi S, Kumar A, Arya TVS. To Study The association of High Sensitivity C-Reactive Protein With Newly Diagnosed DM Type 2. Jornal Indian Academy of Clinical Medicine. 2015; 16(1). 12-15

5. American Diabetes Association. Standards of Medical Care In Diabetes, Diabetes care, 2018; volume 38, supplement 1, page S8-12, S58-60

6. Ramesh SS, Basavaraju MM, Shashikanth YS. A Study of High Sensitive C-Reactive Protein (hsCRP) in Relation to HbAlc in Type 2 Diabetes mellitus in Tertiary Care Hospital, Mysore. International Journal of Contemporary Medicine Surgery and Radiology. 2019; 4(1). 1-3

7. Petchiappan V, Sivakrishna N, Manickam S, Menon S. Glycaemic Control and C-Reactive Protein Levels in Type 2 Diabetes Mellitus-How Well They Corelate? International Journal of Research in Medical Sciences. 2019; 7(5). 1818-21

8. Bruikman CS, Zhang H, Kemper AM, Gils JMV. Netrin family : Role for Protein Isoform in Cancer. 2019; Hindari Journal of Nucleic Acid.

9. Liu C. Li Q, Feng X, Li Q. Elevated Levels of Netrin-1 in The Serum of patients With Diabetic Nephropathy : Relationship With Renal Function and Inflammation. European Journal of Inflammation. 2018; 16. 1-16
10. Yimer EM, Zewdie KA, Hishe HZ. Netrin as a Novel Biomarker and its Therapeutic Implications in Diabetes Mellitus and Diabetes-Associated Complications. Journal of Diabetes Research. 2018; 1-20

11. Departemen Kesehatan Republik Indonesia, Riset Kesehatan dasar, 2018

12. Yim J, Kim G, Lee BW, Kang ES, Che BS et al. Relationship Between Circulating Netrin-1 Concentration, Impaired Fasting Glucose, and Newly Diagnosed Type 2 Diabetes. Frontiers in Endocrinology. 2018; 9(691). 1-8

13. Liu C. Ke Z. Wang Y. Feng X, Li Q. Zhang Y et al. The Level of Netrin-1 Is Decreased in Newly Diagnosed Type 2 Diabetes Mellitus Patients. BMC Endocrine Disorders. 2016; 16(33). 1-5

14. Ay E, Marakogle K, Kizmaz M, Unlü A. Evaluation of Netrin-1 Levels and Albuminuria in Patients With Diabetes. Journal of Clinical laboratory Analysis 2016; 30. 972-77

15. Gupta UK, Mohapatra TK, Potdar P. Correlation between hs-CRP, HbAlc and Oxidative Stress in Type 2 Diabetic Patients. Asian Journal of Medical Reasearch. 2018: 7(4). 1-6

16. Kiran SR, Mohanalakshmi T, Srikumar R, Reddy P. C-Reactive Protein and Other Markers of Inflammation in Prediction of Cardiovascular Disease in Diabetes. International Journal of Research in Pharmaceutical Sciences. 2017; 8(3). 476-79 